\title{
Features of the Functional State of Patients with The Closed Breaks of Shoulder and Shin at Treatment on Ilizarov
}

\author{
Schurov VA* \\ Russian scientific center, The Restoration traumatology and orthopaedy to the name of akad GA Ilizarov, Russia
}

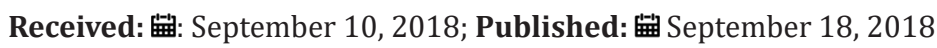

*Corresponding author: Schurov VA, Russian scientific center, The Restoration traumatology and orthopaedy to the name of akad GA Ilizarov, Russia

\section{Abstract}

A comparative survey of stiffness fixation of bone fragments and blood supply to regenerate in two groups of adult patients with closed fractures of the shoulder (35 pers.) and fractures of the tibia (35 pers.) in terms of treatment by Ilizarov. Found that when a shoulder injury significantly lower functional load carried by the limb and 3 times higher than recorded by a load cell micromotion bone fragments when dosed loading segment of the limb. At the turn of the humerus faster and increases blood flow in normal vessels regenerate bone.

Keywords: Fractures of the Humerus; Tibia Fracture; Transosseous Osteosynthesis; The Blood Supply to Regenerate Bone

\section{Introduction}

On the basis of information about the regeneration of the broken bones of front and back extremities experimental zoons a priori had opinion of absence of principle differences in the regeneration of the broken bones of overhead and lower extremities for people. Ilizarov at treatment of patients with the closed breaks of both humeral bone and bones of shin recommended to adhere to the identical optimum terms of fixing - 54 days [1]. Not taken into account thus, that lower extremities, unlike overhead. The feature of the functional state of patients at treatment of break of humeral bone is falling of capacity at the maintainance of lokomotornoy activity. The closeness of proksimal'noy part of shoulder to the corps and necessity of maintainance of motions in an elbow joint do impossible using for treatment of break of humeral bone of typical set of circular supports of vehicle of Ilizarova, in-use at treatment of sick with breaks bones of shin [2]. For the union of breaks of bones a large value is had feature of their providing with blood, more intensive on a shoulder [3-6]. The purpose of the real research was comparison of capacity for the static functional ladening of shoulder and shin, and also inflexibility of fixing of bone fragments and providing with blood of regenerate at treatment on Ilizarov of the closed diafizarnykh breaks of bones of these segments of extremities.

\section{A volume and Research Methods}

Inspected 2 groups of patients. First made 35 patients with the closed diafiz breaks of humeral bone in the conditions of treatment on the method of Ilizarov. Age of patients from 26 to 66 years $(40 \pm 3)$, women - 10 brows., term of fixing in the moment of inspection from 3 to 94 days $(22 \pm 6)$. The second group was made by 35 patients of mature age with the closed diafiz breaks of bones of shin in the conditions of treatment on the method of Ilizarov. For all patients micromobility of fragments of humeral or shinbones was determined at the axial ladening of the proper extremity dosed, step increasing for $5 \mathrm{kG}$ [7]. Thus by tenzometric statio and voltmeter of B7-73/1 a signal, allowing at a count to define the change of distance between spokes, going out from a bone higher and below than area of break, was registered. In addition, by a sensor with bearing frequency $8 \mathrm{Mhz}$ of computer-controlled diagnostic complex «Angiodin-2UK» production amalgamation of «BIOSS» (Russia) speed of blood stream was registered in the area of break on the surface of tibia or on the outward surface of humeral bone at the step increasing functional ladening of shin or shoulder (Figure 1). Statistical treatment of results of researches was conducted by the package of analysis of data of Microsoft ExSel-2010. For the estimation of authenticity of distinctions of results used the t-criterion of St'yudent. Applied the methods of cross-correlation and regressive analysis.

\section{Research Results}

The Most substantial differences in the indexes of two groups of patients are exposed at the estimation of the functional loading on extremity. If able to carry most sick with a break bones of shin 
on the damaged extremity mass of body, for patients with the break of shoulder the maximal loading was $15,9 \pm 1,3 \mathrm{kG}$ and accompanied appearance of the pain feelings. Micromotion of bone fragments in the period of fixing for the patients of 1 th and 2 th groups changed identically, increasing in the first two weeks after osteosintezis because of rezorbtion of ends of fragments. At the breaks of shoulder in the first 2 weeks it made $219 \pm 39 \mathrm{mkm} / 10 \mathrm{kG}$., at the breaks of tibia of $71 \pm 18 \mathrm{mkm} / 10 \mathrm{kG}$. In a subsequent period of treatment mikropomotions of bone fragments in both groups steadily went down because of kompaktizations of bone regenerate (Figure 2). To one of reasons of distinctions in reologic properties of bone regenerate for patients at the beginning of period of fixing there could be features of construction of vehicle of Ilizarov at treatment of traumas of shoulder (not rings, but semi-supports, are used in overhead and lower third of shoulder).

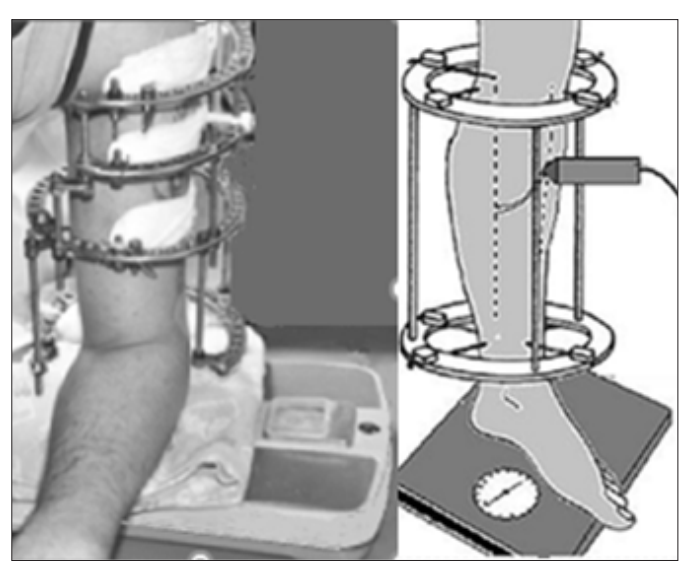

Figure 1: Axial functional ladening of shoulder and shin in the period of treatment of patients on Ilizarov with determination of change of distance between spokes and registration of speed of blood stream.

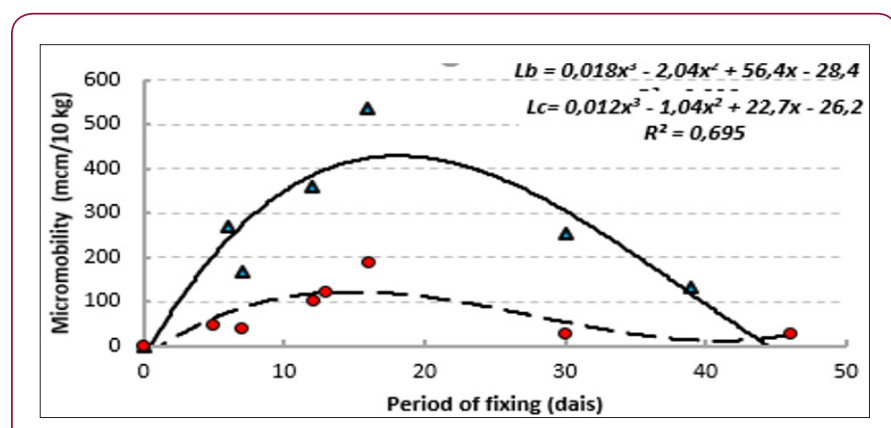

Figure 2: Dynamics of mikromobility of bone fragments at treatment of patients with the breaks of humeral and tibia bone.

Nevertheless, so substantial distinctions in indexes allow to assert that properties of bone regenerate of shoulder differ from properties of regenerate of tibia. Certain differences are exposed and in the indexes of speed of blood stream in vessels bone regenerate of shoulder and shin. Speed of blood stream in regenerate of shoulder was evened $32,4 \pm 3,4 \mathrm{~cm} / \mathrm{s}$, and shins $-26,6$ $\pm 3,2 \mathrm{~cm} / \mathrm{s}$. Speed of blood stream in the vessels of shoulder was most in the first days after a trauma and went down during the first month of period of fixing (Figure 3). Speed of blood stream in the vessels of shin was increased during the first week of treatment and went down during the period of fixing. Speed of blood flow of bone regenerate largely depended on inflexibility of fixing of bone fragments. As far as the increase of mikromobility of fragments to $180 \mathrm{mkm} / 10 \mathrm{kG}$ speed of blood stream was increased as for the patients of 1th group so for patients with the breaks of bones of shin. There were less values of intensity of local blood stream at the large sizes of mikromobility.

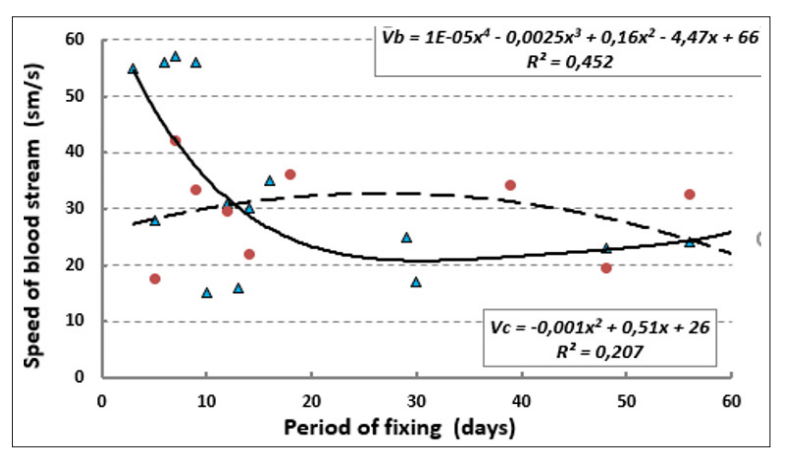

Figure 3: A dynamics of speed of blood stream is in the vessels of bone regenerats of shoulder and tibia.

During the leadthrough of test with an increasing axleloading on a shoulder speed of blood stream in arteries began to go down. Under reaching loading of $15 \mathrm{kG}$ there was a temporal increase of index, related to the decline of intramural pressure in the wall of arteries and diminishing of vascular resistance (Figure 4). The further increase of pressure resulted in the rapid decline of speed of blood stream because of the mechanical ceiling of vascular riverbed and appearance of the pain feelings. The same dynamics of change speed of blood stream was observed and the increase of loading on a shin. It is known that for the vessels of shin in a pose upright characteristically more high blood pressure (action of additional hydrostatical pressure the size of which exceeds 70 $\mathrm{mm}$ of rt.st.). During the leadthrough of research in a pose upright patients with the increase of the functional loading on extremity had a decline of speed.

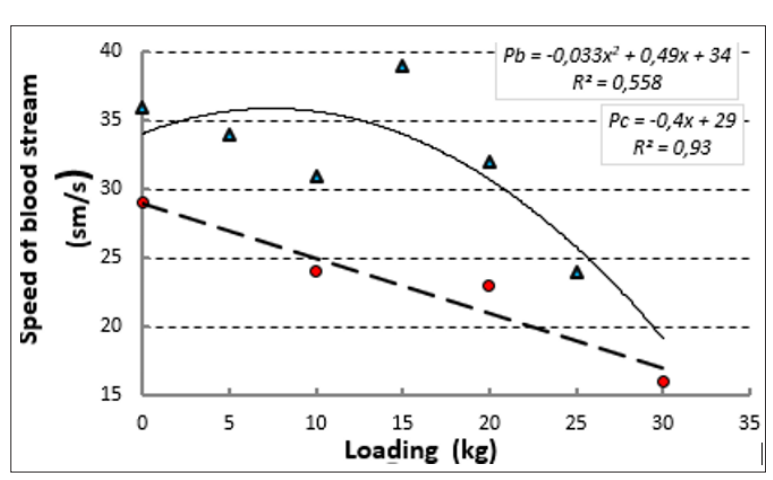

Figure 4: Dynamics of speed of blood stream in regenerate of brachia and tibia at the increase of the functional loading on extremity.

On a background the steady decline of speed of blood stream under reaching loading of $20 \mathrm{kG}$ the relative increase of index is exposed. It allows to draw conclusion that the vessels of bone regenerate of shin are better protected from the action of loading 
enclosed from outside. This defence is determined more high values of hydrostatical pressure and, presumably, by the morphological features of bone regenerate. Thus, the existent difference of functional destiny of overhead and lower extremities for people lays on the imprint on their state in the period of treatment of breaks of bones. Even in the conditions of application of method of Ilizarov there is ability to carry the functional loading at a shoulder less than in 2-3 times below, than at a shin. In the period of treatment of humeral bone considerably anymore pliability of bone regenerate during the leadthrough of test with the functional loading. Speed of blood stream after the break of shoulder.

\section{References}

1. Ilizarov GA, Devyatov AA (1979) Possibilities of transosseous osteosynthesis at treatment of breaks of bones of Scientific Conference. Treatment of breaks and their consequences by the method of transosseous osteosynthesis. Russia, p. 4-8.

ISSN: 2574-1241

DOI: 10.26717/BJSTR.2018.09.001749

Schurov VA. Biomed J Sci \& Tech Res

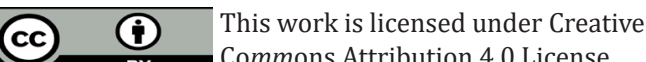

Submission Link: https://biomedres.us/submit-manuscript.php
2. Shevtsov VI, Shved SI, Sysenko Yu M (1995) Treatment of patients with the breaks of humeral bone and their consequences by the method of transosseous osteosynthesis. Russia, p. 224.

3. Lavrischeva GI, Karpov SP, Bachu IS (1981) Regeneration and the blood supply to the bone. Moldova p. 168.

4. Ruchkina IV, D'yachkov VA (2005) Role of soft fabrics the blood supply of breaks and defects of tubular bones (review of literature) Genius of orthopaedy pp. 162-167.

5. Fomicheva A (2007) Morphology and vascularization of humeral bone in connection with the types

6. of build of persons of ripe years of Diss. PhD thesis sciences, Russia, p. 156.

7. Schurov VA, Matsukatov AF (2014) Method of estimation of the state of bone regeneration, Patent Russian Federation.

8. Schurov VA (2014) Pliability and the blood supply of distraction regenerat, The Russian journal of biomechanics pp. 471-478.

\begin{tabular}{ll} 
BIOMEDICAL & Assets of Publishing with us \\
RESEARCHES & - Global archiving of articles \\
& - Immediate, unrestricted online access \\
\hline hiss: $2574-1241$ & - Rigorous Peer Review Process \\
\end{tabular}

